\title{
Determinants of social inequalities in child mortality in Mozambique: What do we know? What could be done?*
}

\author{
Gloria Macassa* and Bo Burström \\ Department of Public Health Sciences, Division of Social Medicine, Karolinska Institutet, SE 171 \\ 76 Stockholm, Sweden. \\ * Address for Correspondence: E-mail: Gloria.Macassa@phs.ki.se; Phone: + 46 (08) 7373886 \\ Telefax: +46 (08) 307351
}

\begin{abstract}
SUMMARY
Health inequalities are no longer an issue only for developed countries. In recent years there is agreement that all countries present health inequalities regardless of their level of wealth. In low-income countries and especially in sub-Saharan Africa where the majority of the poor people live as well as their children, research on child health inequalities is still scarce. This review of evidence suggests that if Mozambique is to achieve the millennium development goals (MDGs) by 2015 further research on important determinants of disparities in child mortality is urgently needed.
\end{abstract}

[Afr J Health Sci. 2006; 13:139-143]

*Published online before print

\section{Introduction}

Health inequalities are no longer an issue only for developed countries [1]. In recent years there is agreement that all countries present health inequalities regardless of their level of wealth [1,2]. In low-income countries, research on health inequalities and especially child health inequalities still in its infancy and especially in Sub-Saharan where the majority of the poor people live as well as their children.

The concept of health inequalities implies the study of groups of individuals, which to some degree share their social circumstances and/or are similarly disadvantaged, or privileged, as a group. Individuals have social positions, but the meaning of these cannot be understood unless they are perceived in the social context in which people live. The social stratification of a society, that is the hierarchy of individuals in terms of wealth, power and prestige, generates inequalities in the distribution of material and non-material goods and assets. One's position in the social system is strongly associated with life chances, opportunities and living conditions, and thereby also has a significant influence on chances of good health [3]. In low-income countries when regarding children, behavioural explanations of social differentials in health broadly focus on hygiene practices and lack of maternal knowledge as well as cultural practices influencing child rearing and food preparation and consumption as the main determinants of adverse child health outcomes. Structural explanations stress the socioeconomic, societal and environmental influences on families, which differ and to some extent determine cultural patterns of behaviour and individual knowledge and hygienic practices. The dominant schools of thought on health inequalities in both developed and low-income countries are the structural and the behavioural: the structural school maintains that inequalities arise as a result of differences in the socio-economic structure of society which lead to poverty and its health consequences, the behavioural school holds that cultural and behavioural 


\section{SHORT COMMUNICATION}

patterns associated with and contributing to poverty explain much of the observed difference in health outcomes. Maternal education is universally accepted as an important determinant of child health in lowincome countries. In many studies of health inequalities, maternal education is taken as the main indicator of socio-economic position (SEP), whilst in others it is seen as a marker of cultural level and an explanation of observed SEP differences in child health outcomes [4]. Water and air-borne diseases are responsible for a large part of the child mortality and morbidity in low-income countries [4]. Explanations for the high prevalence of these diseases and their concentration among the poor in low-income countries have focused on hygiene, cultural practices, family size, overcrowding, maternal education, water availability and living conditions. In the same way as advocates of behavioural explanations for inequalities in present day developed countries, advocates of the behavioural school in low-income countries concentrate on the individual family, and usually the mother within the family. Differences in hygiene and knowledge as well as culturally determined practices are presented as the main explanations for adverse outcomes in early childhood [4].

These assumptions are challenged by the structural school on the basis that individual behaviour and cultural factors are themselves closely linked to SEP. For example, maternal education universally accepted as an important determinant of child health outcomes in lowincome countries, is itself positively correlated with higher SEP and governments through social policies can modify it $[5,6]$. In Mozambique, few studies have addressed health inequalities and especially in child health although the country still experience high levels of child mortality. In a study measuring total health inequality in fifty lowincome and middle-income countries, Mozambique was found to have the largest inequalities in child survival [7]. The aim of this paper is to examine existing evidence on determinants of inequalities in child mortality in Mozambique and discuss the need for further investigation into other important determinants.

\section{Socioeconomic determinants}

Place of mother's residence (urban/rural), migration [8], civil war $[8,9]$ and Structural Adjustment Program have been shown to influence child survival in Mozambique. Children of mother's living in urban areas of the country have lower mortality compared to children living in rural area [8]. However, using data from the 1997 Demographic and Health Survey it was found that infant, child and under-five mortality were higher in urban than in rural areas between 1994-1997 [8]. Rural to urban migration and civil war were suggested as possible explanations behind the increased urban mortality rates during that period [8].

Education and occupation are also associated with child mortality in Mozambique. The association is much stronger with education, where children whose parents with primary or more education have the best chances of survival. Furthermore education of the parents seemed to be a better measure of socio-economic position when attempting to study child health inequalities [10]. The importance of education as a measure of socio-economic position, especially the education of the mother has been found in other developing countries [6]. The only existing evidence on the relationship between child mortality and parental socioeconomic position (SEP) by means of education did also show that father's education was important to child survival [10]. Parental occupation has not been an ideal measure of socio-economic position, since many people are classified as unemployed in the Mozambique surveys, especially the DHS survey. This is further complicated by the fact that the majority of the considered unemployed are women who work in informal markets [10]. However, although the role of place of residence, education and occupation as determinants of social differentials in child mortality in the country is known, very little or nothing is known on the role of income and land possession. Income has been associated with inequalities in child mortality in many western countries [11,12] and in some developing countries as reflected in studies that have been carried out $[13,14]$. However, in recent years studies have found no effect of 


\section{SHORT COMMUNICATION}

income inequality on population health in developed countries $[15,16]$ as well as in some developing countries [17]. In Mozambique, since the majority of the population $(70 \%)$ lives in rural areas [18], other wealth measures rather than income should be investigated. For instance it would be helpful to define a household wealth that includes material possession, land possession and cow ownership. A study in rural Karachi found that land possession had a very strong relationship with child death [19]. Another socio-economic determinant that should be investigated is parental region of residence. This is important since there are striking regional socio-economic inequalities that might influence child survival chances. For instance no study to our knowledge has addressed mortality or other child health outcomes by parental region of residence.

\section{Proximate determinants}

Household environment was found to be associated with child mortality in urban areas of Mozambique and the association was partly explained by demographic and socioeconomic variables especially maternal education [20]. This is in agreement with findings in other developing countries [21]. However, future research should investigate the role of household environmental factors in rural areas of the country.

Using the 1997 DHS, a first assessment of the role of mother's ethnic affiliation measured by the first language she spoke, indicated that there was a very strong statistically significant relationship between ethnicity and under-five mortality in the country. The relationship between ethnicity and under-five mortality was explained by demographic, socioeconomic and household environment factors [18]. Thus, qualitative studies are needed to investigate parental customs, beliefs and ultimately behaviours that my influence child health. Within the proximate determinants more research is needed into the impact of health service utilization on child mortality. This is very important due to the very high levels of infant mortality as well as maternal mortality experienced in the country, some of which may be amenable to health service intervention. In addition, utilisation should also be investigated in relation to access to services. On the other hand, evidence shows that as it is the case in other developing countries, young and old age of the mother at the child's birth, first and higher birth orders and a preceding birth interval of less than twenty four months are all related to high risks of child mortality, especially in the first years of life [18]. Furthermore, research is needed to understand the determinants of neonatal and postneonal mortality. It is suggested that perinatal mortality is an indicator of the standard of health services while postneonatal mortality is an indicator of socio-economic development and is linked to household environmental conditions [18].

\section{More needs to be done}

The 1997 demographic health survey (DHS) has helped to understand some determinants of child mortality in Mozambique and eventually results of the second DHS survey carried out in 2003 will further shed light on possible determinants. However, if Mozambique is to try to achieve the Millennium Development Goals (MDGs) it is important for the country to develop a solid and reliable data base collection (from surveillance systems, vital registration). The understanding of child health epidemiology at the country level is important in order to select the appropriate type of interventions. It is argued that each country characteristics are strongly connected with its epidemiological profile. Bryce and others suggested that child mortality interventions should be selected based on local epidemiological data [22]. On the other hand Mozambique must make efforts to collect information on causes of death that can help understand the mortality differentials associated with the above-mentioned determinants. Verbal autopsy might become a useful tool while registration systems are still improving. In 1994, a study of registered and autopsied deaths found that perinatal disorders, malaria and diarrhoeal disease were the three leading causes of death in Maputo city [23].

Increased knowledge on the effects of poverty on child mortality and other child health outcomes (nutrition, health services) is needed. Furthermore, if this knowledge is based on good quality data as well as solid 
epidemiological research may contribute to effective interventions needed by the poorest children and their families.

\section{References}

1. Braveman $\mathrm{P}$ and Tarimo E. Social inequalities in health within countries: not only an issue for affluent nations. Social Science and Medicine. 2002; 54:1621-1635.

2. Braveman $\mathrm{P}$ and Tarimo E. Social inequalities in health within countries: not only an issue for affluent nations. Social Science and Medicine. 2002; 54:1621-1635.

3. Evans T; Whitehead M; Diderichsen F; Bhuyia A and Wirth M. Eds. Challenging inequities in health: From ethics to action. New York: Oxford, 2001.

4. Lynch J and Kaplan G. Socioeconomic Position. In Berkman LF, Kawachi I (eds). Social Epidemiology. Oxford: Oxford University Press, 2000.

5. Spencer N. Poverty and child health. Oxford: Radcliffe Medical Press, 199

6. Caldwell $J$ and McDonald P. Influence $f$ maternal education in infant and child mortality levels and causes. Health Policy Education. 1982; 2:251-267.

7. Buor D. Mothers education and childhood mortality in Ghana. Health Policy. 2003; 64:297-309.

8. Gakidou E and King G. Measuring total Health Inequality: adding individual variation to group-level differences. International Journal for Equity in Health. 2002; 1:3

9. Macassa G; Ghilagaber G; Bernhardt E and Burström B. Trends in infant and child mortality in Mozambique during and after a period of conflict. Public Health. 2003; 117:221-227.

10. Garrene ML; Coninx R and Dupuy C. Effects of the civil war in central Mozambique and evaluation of the intervention of the International Committee of the Red Cross. Journal of Tropical Paediatrics. 1997; 43:318-323.

11. Macassa G; Ghilagaber G; Bernhardt E; Diderichsen $F$ and Burström $B$. Inequalities in child mortality in Mozambique: differentials by parental socio-economic position. Social Science and Medicine. 2003; 57:2255-2264.

12. Lynch J; Smith GD; Hillemeir M; Shaw M; Raghunatan $\mathrm{T}$ and Kaplan G. Income inequality, the psycho-social environment and health comparisons of wealthy Nations. Lancet. 2001; 358:194-200

13. Rodgers GB. Income and inequality as determinant of mortality: an international cross-section analysis. International Journal of Epidemiology. 2002; 31:533538

14. Alves D and Beluzzo W. Infant mortality and child health in Brazil. Economic and Human Biology. 2004; 3:391-410.

15. Wang L. determinants of child mortality in LDCs: empirical findings from Demographic and Health Surveys. Health Policy. 2003; 65:277-299.

16. Lynch J, Davey Smith G, Harper S, Hillemeier M, Ross N, Kaplan G, Wolfson $\mathrm{M}$ et al. Is income inequality a determinant of population health? Part 1: A systematic review. Millbank Quarterly. 2004; 82:5-99

17. Shmueli A. Population health and income inequality: new evidence from Israeli time-series analysis. International Journal of Epidemiology. 2004; 33:31117.

18. Chung W. Income inequality in health: evidence from Indonesia. Singapore: National University of Singapore, 2002.

19. Macassa G. Poverty and health in different contexts: Social inequalities in child mortality in Mozambique and $19^{\text {th }}$ century Stockholm. Stockholm. Almqvist and Wiksel International. $2004(\mathrm{PhD}$ dissertation)

20. Darkin MS; Islam S; Hassan ZM and Zaman SS. Measures of socioeconomic status for child health research: comparative results from Bangladesh and Pakistan. Social Science and Medicine. 1994; 38:1289-1297.

21. Macassa G; Ghilagaber G; Bernhardt E and Burström B. Contribution of household environment factors to urban childhood mortality in Mozambique. East African Medical Journal. 2004; 81:408414.

22. Checkley W; Gilman RH; Black RE; Epstein L; Cabrera L and Sterling CR. 


\section{SHORT COMMUNICATION}

Effect of water and sanitation on childhood health in a poor Peruvian periurban community. Lancet. 2004;10:112118.

23. Bryce J; el Ariffven S; Parlyo G; Lanata CF Gwatkin D and Habitch J-P and the Multy-country Evaluation of IMCI Study group. Child survival III: Reducing child mortality: can public health deliver?.Lancet.2003; 362:159-164.

24. Dgedge M; Novoa A; Macassa G; Sacarlal J; Black J; Michaud C and Cliff J. The burden of disease in Maputo City, Mozambique:registered and autopsied deaths in 1994. Bulletim of the World Health Organization, 2001; 79:546-552. 